\title{
Open
}

\section{Enhancing the Inclusion of Vulnerable and High-Risk Groups in Demand-Side Health Financing Schemes in Cambodia: A Concept for a Risk-Adjusted Subsidy Approach}

\author{
Ralf Radermacher $^{\mathrm{a}}$, Siddharth Srivastava ${ }^{\mathrm{b}}$, Matthew Walsham ${ }^{\mathrm{c}}$, Chhorn Sao $^{\mathrm{d}}$
} and Francesco Paolucci ${ }^{\mathrm{e}, \mathrm{f}}$

${ }^{a}$ Deutsche Gesellschaft für Internationale Zusammenarbeit (GIZ), 10/319, Mtendere Drive, Lilongwe 3, Malawi.

${ }^{\mathrm{b}}$ Swiss Tropical and Public Health Institute, Socinstrasse 57, 4002 Basel, Switzerland.

${ }^{\mathrm{c}}$ Independent consultant, U.K.

${ }^{\mathrm{d}}$ Social Health Protection Association (SHPA), \#54, St. 598, Sangkat Beong Kok II, Khan Toul Kork, Phnom Penh, Cambodia.

${ }^{\mathrm{e}}$ Sir Walter Murdoch School of Public Policy and International Affairs, Murdoch University, South Street, Murdoch 6000 WA, Australia.

${ }^{\mathrm{f}}$ School of Economics, Management \& Statistics, University of Bologna, Piazza Scaravilli 2, 40100 Bologna, Italy.

Efforts are currently under way in Cambodia to expand the population coverage of social health protection schemes (health equity funds and voluntary insurance). Aligning the benefit packages for members of such schemes poses particular challenges in relation to the insurance component, as the financing of direct benefits in the insurance relies largely on the collection of voluntary premiums. This paper develops the concept of a targeted "risk-adjusted subsidy" approach to address this issue. Data on the health-seeking behaviour of insured households from Kampong Thom district over the course of one year (2010) are used to illustrate the concept. To retain the currently applied community rating and set incentives for cost effectiveness in administrative costs, as well as to avoid cream skimming (focusing on "good risks"), a risk-adjustment mechanism is proposed that would provide ex ante subsidies to insurance schemes according to the expected additional cost of a person joining the scheme. Although the concept is developed using the example of Cambodia, it is equally applicable to all developing countries facing fragmented risk pools while aiming for universal health coverage.

The Geneva Papers (2016) 41, 244-258. doi:10.1057/gpp.2016.5

Keywords: risk adjustment; microinsurance; universal health coverage; health insurance

Article submitted 22 June 2015; accepted 25 January 2016; published online 2 March 2016

The online version of this article is available Open Access

\section{Introduction}

In Cambodia, the poorest quintile of households is identified through a mechanism implemented by the Ministry of Planning. Health-care costs for these households are covered through "health equity funds", , which are government and donor funded and provide a

\footnotetext{
${ }^{1}$ Annear et al. (2015).
} 
targeted subsidy to the poor. These subsidies help the poor to access primary and secondary health-care services.

Income differences between the "identified poor" (lowest quintile) and the second and third quintiles are relatively small, ${ }^{2}$ and the probability of catastrophic health expenditure is actually higher among the "near-poor" than those in the bottom quintile. ${ }^{3}$ Furthermore, the Ministry of Planning's pre-identification process is carried out irregularly (approximately every three years), whereas poverty is dynamic in nature. As such, the extension of social health protection (SHP) to the near-poor is necessary if the risk of impoverishment through ill health is to be addressed in the informal sector as a whole. Consequently, a number of NGOs have developed not-for-profit micro health insurance (MHI) ${ }^{4}$ schemes for this target group that provide access to primary health care at public health centres as well as to inpatient services at one or more public hospitals. In addition, all schemes cover the cost of transportation in emergencies and most provide a funeral grant in case of death.

Previously, such schemes were established on an ad hoc basis, largely dependent on the geographical focus of the NGO operating the scheme and the availability of donor support. More recently, attempts have been made to integrate some insurance schemes with other SHP mechanisms, in particular, with health equity funds.

The development of integrated SHP schemes includes efforts to align the benefit package for all members, especially in terms of direct medical benefits. However, this poses particular challenges for the MHI component of integrated schemes because the financing of benefits for voluntary members relies largely on premiums, which, in most cases, are insufficient to meet the cost of existing benefits provided by such schemes. An analysis of operational data on members of the Social Health Protection Association ${ }^{5}$ in 2012 found that schemes were paying an average of USD 5.50 (ranging from USD 4.50 to USD 8.80) for direct benefits (payments to facilities and transportation and funeral costs), against an average contribution of USD 3.75 (ranging from USD 3.40 to USD 4.70). This resulted in an average deficit of USD 1.75 per member, even before administrative costs were taken into account (which varied from between USD 1.30 and USD 2.00 per member).

Increasing the premium paid by members is perceived by most MHI operators to be impractical in the current Cambodian context, where the general public's understanding of insurance principles, perception of public health services and associated willingness to pay premiums pose constraints. Indeed, recent experience has shown that schemes with premiums above USD 7.00 have been unable to attract more than 3 per cent of the target population (e.g. in Siem Reap, Pearaing and Phnom Penh), compared with schemes with more affordable premiums, some of which have achieved coverage of more than

\footnotetext{
${ }^{2}$ Index Mundi (2014).

${ }^{3}$ Ministry of Health (2012).

${ }^{4}$ In Cambodia, not-for-profit micro health insurance is often referred to as "community-based health insurance" (CBHI). However, in international contexts, CBHI generally refers to grass-root insurance schemes owned and run by communities, which are, by nature, usually small in scale. In Cambodia, despite the widespread use of "CBHI" as a term, most of these schemes are run by NGOs and operate on a significant scale with the capability of further scaling-up their operations if resources become available. To avoid misunderstanding, the term notfor-profit micro health insurance will be used for the purposes of this paper.

5 The Social Health Protection Association (SHPA) is a membership organisation that brings together all NGO operators of social health protection schemes across Cambodia, including every organisation running not-forprofit micro health insurance and several health equity fund implementers.
} 
50 per cent (e.g. in Angkor Chum). At the same time, most operators are facing severe funding pressure, as donor finance has been decreasing while the government has yet to articulate a clear operational vision for the expansion of SHP in the context of efforts to achieve universal health coverage.

As such, the need to ensure that premiums remain affordable places significant constraints on the services that can be included within the benefit package of insurance schemes such as high-cost national-level hospital services, and specific services for chronic diseases such as diabetes. At the same time, emerging donor priorities and the overall Government of Cambodia SHP framework are placing increasing emphasis on the enrolment of vulnerable individuals (such as the elderly, children, people with disabilities and pregnant women) into schemes. ${ }^{6}$ Schemes are thus confronted with the challenge to remain financially viable, while ensuring that high-risk groups are covered and that associated high-cost services are included in the benefit package. Consequently, scheme implementers have been calling for government subsidies either for, among other things, administrative costs or to shift excess health-care costs to the government or donors ex post. ${ }^{7}$ This, however, has met with resistance, as such approaches can distort incentives for the effective management of scheme costs (both for administration costs and those associated with direct benefits).

As a contribution to the discussion, this paper presents an alternative approach to subsidies -one that retains incentives for efficient scheme management as well as for broad-based enrolment efforts, including of high-risk groups. The concept is based on the notion of a "risk-adjustment mechanism" and is designed to be suitable for countries such as Cambodia that are moving towards universal health coverage through the development and expansion of demand-side financing mechanisms (such as insurance) in the presence of multiple and fragmented risk pools.

Risk-adjustment mechanisms are used in several competitive health insurance markets to compensate an insurer for taking on high-risk individuals. The subsidy is paid to the insurer, not the insured, but is based on the insured's risk profile. ${ }^{8}$ This mechanism prevents insurers from increasing the premium for such individuals or avoiding taking on the risk, ${ }^{9}$ and thus allows for broad-based enrolment in insurance schemes in the spirit of universal health coverage. By reducing the costs imposed by high-risk individuals to the overall pool, such mechanisms help keep premiums at affordable levels while retaining incentives for efficient health-care production. ${ }^{10}$

Risk-adjustment models should be based on an accurate description of the risk profile of each insured, that is, on a forecast of the expected costs they would induce. A risk profile could contain information on age and gender, but also on the health history of the insured. Reliable information on diseases-particularly in relation to the specific characteristics of a person such as age and gender-is, however, scarce and often of low quality in the developing world. ${ }^{11}$ But this lack of data can be circumvented by using instead easily

6 For instance, GIZ (2014).

7 SHPA (2013).

8 Van de Ven (2011).

9 Paolucci et al. (2006); Paolucci and Stoelwinder (2011).

${ }^{10}$ Armstrong et al. (2010).

11 Byass (2009). 
observable characteristics which can provide a fair descriptor of the expected costs that an individual might contribute to the risk pool and, hence, offer an adequate distinction between high(er) and low(er) risk groups. ${ }^{12}$

This conceptual paper uses data from an MHI in Cambodia to illustrate the differences in health-care utilisation cost per case and expected cost to the scheme (which would form the basis for the risk premium) according to gender and age. Based on this illustration, a concept is derived for provision of an ex ante subsidy to such insurance schemes, which would reduce the costs borne by the insured, making the scheme indifferent to the risk profile of each insured, while at the same time retaining the incentive for efficient operations. The paper begins with an overview of the data used to provide insights into health-care utilisation and the costs of insuring members in an MHI, after which the subsidy concept is presented and the advantages of this approach explored.

\section{Methodology: data and limitations}

In order to better understand health-care utilisation and the cost of insuring members, it was deemed helpful to use real data on health insurance claims received by MHIs in Cambodia. However, reliable data from insurance schemes on individual members' health-care utilisation and related costs, as well as the age and gender of the patient, is scarce in Cambodia. The introduction of a standardised Management Information System for all integrated SHP schemes and MHI providers through the Ministry of Health, the roll-out of which is currently under way, will likely improve this situation.

For the presentation of this concept, data from a single scheme operating in the Kampong Thom "operational health district" 13 were used. The data set covers the period January to December 2010 and contains a total of 9,898 events (consisting of a combination of medical costs along with transportation costs and payments for "safe motherhood" services) claimed by health-care providers from the insurance scheme. The data set contains information on the kind of provider used, the type of service received (outpatient vs inpatient) and the amount claimed from the insurance scheme, as well as information on the age and gender of the patient, although information on specific diseases was unreliable.

Under the MHI selected for this study, households were allowed to enrol in the scheme at any time and for varying durations. Hence, the scheme had fluctuating monthly membership figures in 2010 ranging from 3,018 in January (lowest monthly figure) to 4,678 in June (highest monthly figure). On average, about 1,950 males and 2,045 females were members of the scheme. The utilisation rate was calculated on a monthly basis as a ratio of the number of visits to health facilities (claims received by the scheme) to the total number of people insured in that month. The monthly incidence rates were then aggregated to obtain the annual incidence rate. The annual premium (calculated as the incidence rate times the average cost) was also calculated in the same manner, that is, monthly pure risk premium figures calculated and aggregated to obtain the annual premium. STATA and Excel were used for the calculations.

\footnotetext{
${ }^{12}$ For instance, Mahal et al. (2002) provide a compilation of studies that show how health costs increase in old age.

13 An "operational health district" is an administrative unit in the Cambodian health system.
} 


\section{Results and discussion}

\section{Health-care utilisation}

An analysis of health service utilisation data revealed differences in the utilisation rate between men and women, as well as across different age groups. Individuals enrolled in the insurance scheme visited health centres on average 2.26 times in a year. However, the average for men and women differed, with average rates of health service utilisation of 1.72 and 2.76 per year, respectively. Health centre utilisation by women increased at the onset of child-bearing age; health centres in Cambodia are usually the main source of obstetric care for women, including for actual delivery. Figure 1 illustrates the average number of visits to a health centre by age group and for men and women.

The average hospitalisation (inpatient treatment) rate for the entire sample across all age groups was 0.10 per year, which is high compared with earlier rates collected for health equity funds (which were between 0.008 and 0.048 for three sample sites). ${ }^{14}$ This high utilisation rate can be explained by adverse selection: more than half of the households that utilised inpatient care joined the scheme in the preceding three months. Figure 2 illustrates differences between age groups for men and women in the hospitalisation rate.

\section{Cost of health-care utilisation}

The average cost of health-care utilisation paid by the insurance scheme differs greatly between hospitals and health centres, as can be seen in Table 1. These figures are based on 2010 prices; however, the cost of care has increased since then. Disaggregating the costs by age and gender has only limited value in this context, as these results need to be weighted with the incidence of health-care utilisation by the specific subgroup to provide

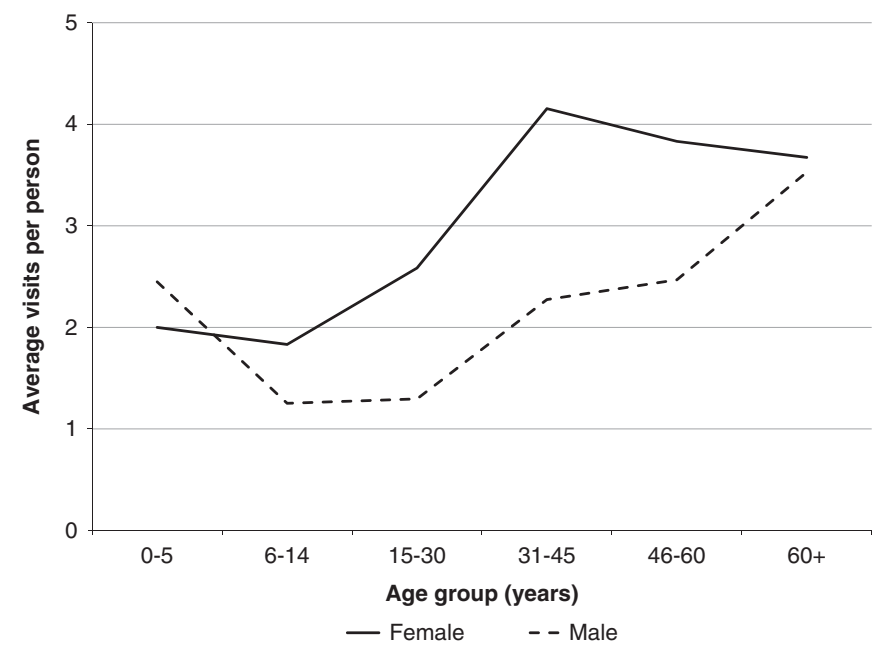

Figure 1. Outpatient (health centre+hospital) service utilisation by age and gender.

\footnotetext{
${ }^{14}$ Noirhomme et al. (2007).
} 


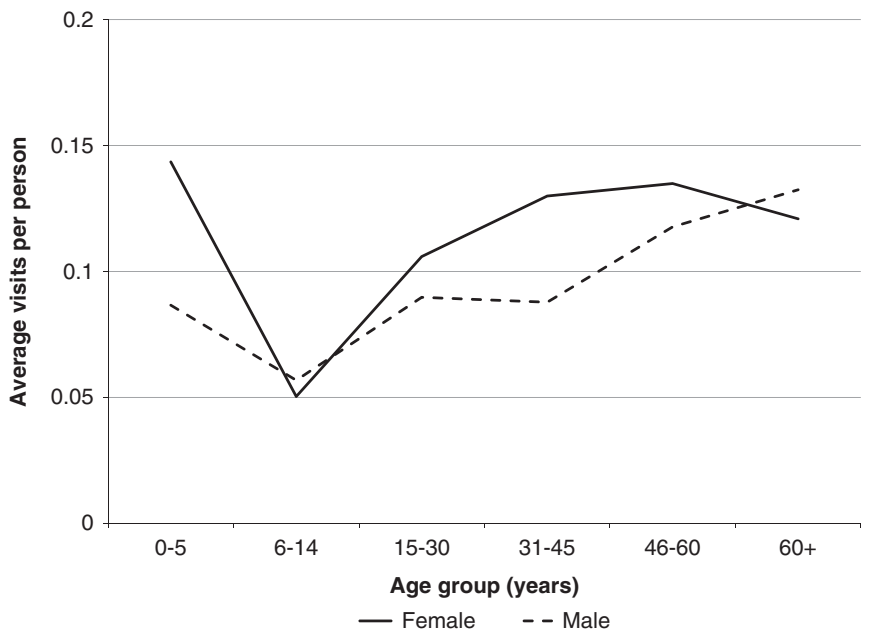

Figure 2. Inpatient (hospital only) service utilisation by age and gender.

Table 1 Mean costs claimed by different facility levels

\begin{tabular}{lrcr}
\hline & $N$ & Mean (Cambodian riels) & St. Dev. \\
\hline Health centre & 9,044 & $1,668.94$ & $8,228.36$ \\
Hospital (IPD+OPD) & 854 & $49,906.32$ & $51,409.27$ \\
\hline
\end{tabular}

information about the expected average costs to the insurance scheme of a person of a specific age/gender subcategory.

\section{Expected average cost incurred by the insurance scheme}

The insurance contribution required by a scheme is a function of the severity of risk (cost) and its frequency of occurrence. Contribution can be calculated in relation to the risk contributed by each individual in the pool (so-called "risk-rated approach" or "risk rating") or across the entire risk pool, resulting in a flat per capita contribution per head (so-called "community rating"). ${ }^{15}$ Figure 3 depicts the different contribution rates for the data being presented; differentiating the rates by age and gender results in considerable differences for men and women for most age groups and a clear cost increase for men with age. A flat premium per head for women regardless of their age would be much higher (at around 17,896 riels) than a flat premium for men (10,772 riels). From the time they enter the child-bearing age range, women constitute a high(er) risk group. Figure 4 combines men and

\footnotetext{
${ }^{15}$ Smith and Witter (2004, p. 6).
} 


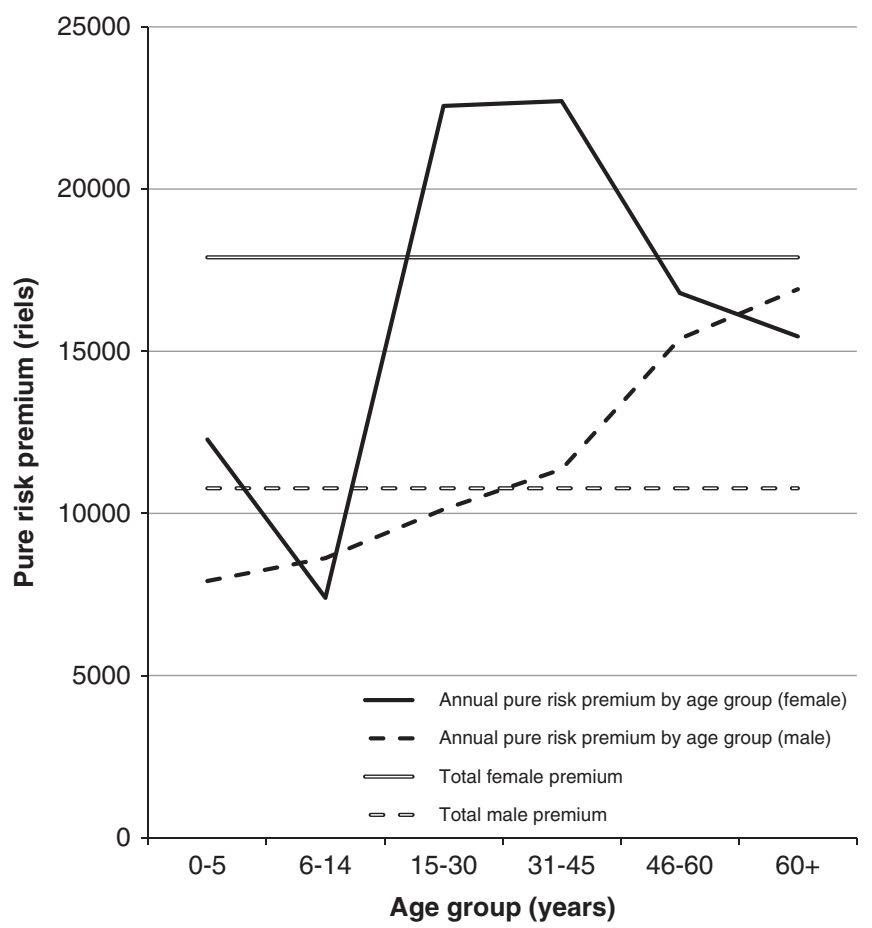

Figure 3. Annual pure risk premium (outpatient+inpatient) by gender and age group.

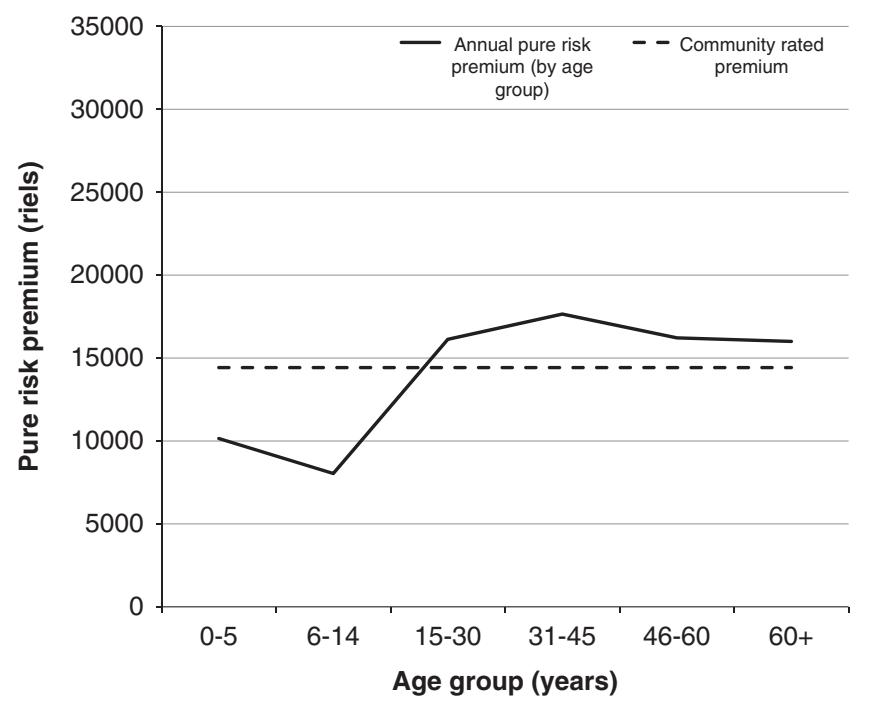

Figure 4. Annual pure risk premium (outpatient+inpatient) by age group. 


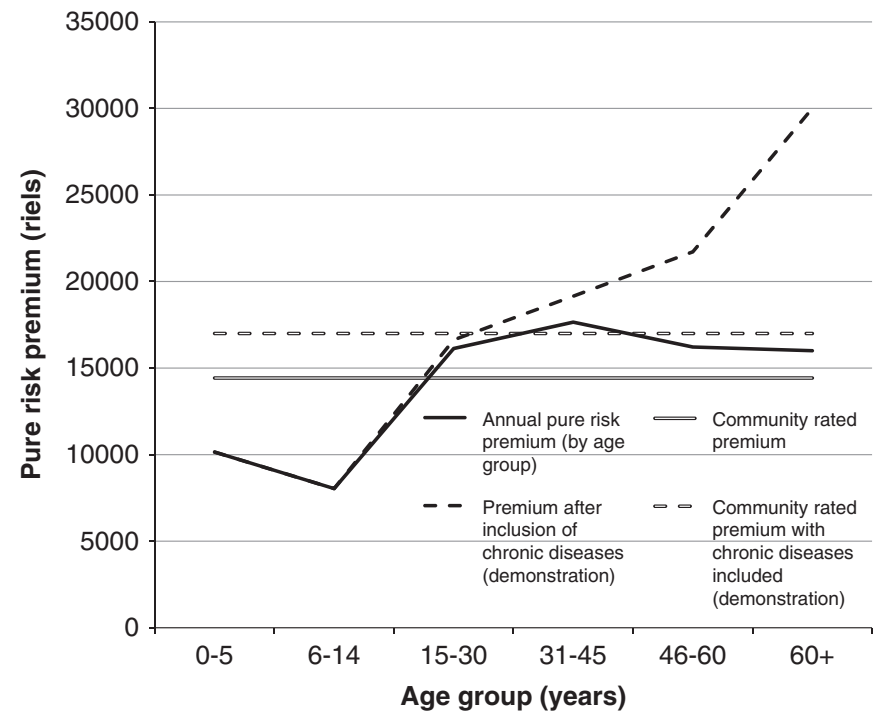

Figure 5. Annual risk premium across age groups (figures used are hypothetical), including chronic care.

women into a single curve depicting the increasing cost with age even more clearly. A regression was used to explain the expected cost of an individual (premium) through age and gender categories (along with variables to include the age and gender interaction effect), and an $F$-test on the regression coefficients confirmed a statistically significant difference (Prob $>F=0.0285$ ). Further testing on the specific effects of age categories revealed a statistically significant difference at 0.1 threshold value (Prob $>F=0.0827$ ). The difference across age groups in females was observed to be similar to males.

In addition to these findings based on the existing basic package of services, as the 2010 STEPS report ${ }^{16}$ suggests, a similar relationship exists between age and the incidence of major chronic diseases (high blood pressure, diabetes and high cholesterol). Hence, if high cost services for chronic diseases currently excluded from the benefit package were taken into account, the general trends illustrated above would remain similar, but the overall costs for older groups would be even higher. Figure 5 illustrates this point conceptually, as the insurance data set and the data used in the STEPS Report could not be combined.

\section{An approach for enhancing the inclusion of vulnerable and high-risk groups}

The data show that differences in the expected costs incurred by an insurance scheme can be forecast using relatively easily observable characteristics of individuals. Working with these

${ }^{16}$ Sophal et al. (2010); the STEPS Non-communicable Disease Risk Factor Survey is part of the STEPwise approach to surveillance (STEPS) Adult Risk Factor Surveillance project by the World Health Organization (WHO). 
easily observable characteristics can be an advantage, particularly where data in the health sector are weak or unreliable.

In all Cambodian MHI schemes, as with most health insurance schemes that focus on the informal sector, a community rating is applied to ensure all members have access to the scheme at the same cost. Although this is desirable from a social point of view, it poses an economic challenge for the insurance scheme: the insurance product is more attractive to those individuals with average expected health costs higher than the per capita contribution - and household enrolment is not always fully enforced, also because reliable records on household composition are often not available. The phenomenon of attracting above-average risks is called "adverse selection". ${ }^{17}$ Although, from a social point of view, this might be desirable, as it helps to ensure that the most vulnerable households are protected and increases access to health care for those who are most likely to need it, ${ }^{18}$ over-representation of higher-risk subgroups increases the financial instability of insurance schemes and may even lead to a counter-reaction in which schemes aim to reduce the participation of such higher-risk groups (so-called "cream skimming"19). In reality, both of these phenomena are undesirable, particularly when-as in the case of Cambodia-MHI is an integrated component of SHP schemes, which are meant to constitute a stepping stone towards comprehensive universal health coverage, as outlined above.

To avoid such an undesirable development, a mechanism could be introduced at the national level that applies a risk-adjustment $\operatorname{logic}^{19}$ and is, at least to begin with, fully funded by the government, donors or both. This mechanism would provide ex ante subsidies based on the expected additional cost (risk) that a person joining the insurance scheme constitutes to the risk pool beyond a set threshold. This risk-adjusted subsidy mechanism could eventually be institutionally anchored in a dedicated SHP agency or fund at the national level, as is currently being discussed in Cambodia. ${ }^{20}$ The SHP schemes would submit their MHI membership information at set intervals to the risk-adjusted subsidy fund at the national agency and receive an ex ante subsidy payment in return.

The subsidy payable for each person covered by MHI can be calculated using the following formula:

$$
S_{i}=\operatorname{Cost}_{i}+S M_{i}+A_{j}-C_{j}
$$

where $S_{i}$ is the subsidy payment for the specific individual ( $\left.i\right)$ in question with $S_{i} \geqslant 0$, and Cost $_{i}$ is the pure risk premium (i.e. expected cost) of the specific individual, $S M_{i}$ a security margin (i.e. mark up on the pure risk premium to account for stochastic variations in the expected costs), $A_{j}$ the administrative cost per person (which is not strictly dependent on the personal characteristics of an insured indicated with subscript $j$ ) and $C_{j}$ a fixed contribution payable per person regardless of their specific risk profile (age, gender). $C_{j}$ can be politically defined in line with current discussions based on the draft Health Financing Policy, which envisages the use of general government revenue or earmarked taxes to subsidise the enrolment of the informal sector in a "National Social Health Protection Fund". ${ }^{20}$

\footnotetext{
${ }^{17}$ See, for example, Akerlof (1970); van de Ven and Ellis (2000).

${ }^{18}$ For a review of the potential impact of micro health insurance, see Radermacher et al. (2012).

19 Van de Ven and Ellis (2000).

${ }^{20}$ Ministry of Health (2013).
} 
$\operatorname{Cost}_{i}$ is mainly defined by the health-care benefits covered by the MHI. Currently, benefit packages for MHI vary by scheme and differ from the standard benefit package for health equity funds, especially in terms of access to higher-level hospital services. In the future, the intention is to mandate a minimum benefit package for all members of integrated SHP schemes, including those covered by MHI, and this decision will rest with the government as the main source of subsidies to schemes (i.e. in defining the essential benefit package, as discussed in the current draft Health Financing Policy). Beyond this, it is mainly a function of the characteristics of age and gender, as illustrated above. However, costs will also differ by location due to different illness patterns and the cost structure of surrounding health-care providers. Cost $_{i}$ can, therefore, be estimated using multiple linear regression defined by the following formula:

$$
\text { Cost }_{i}=\alpha \text { Age }_{i}+\beta \text { Gender }_{i}+\gamma \text { Location }_{i}+\mu_{i},
$$

where $\alpha, \beta$ and $\gamma$ are the regression coefficients of the three characteristics, respectively (i.e. the estimators describing the cost function based on previous claims data). Interaction terms will be added to reflect the simultaneous influence of the three factors on cost. The precision of the estimate will increase steadily over time as longer time series data become available the longer this approach is implemented. Finally, $\mu$ is the residual error term.

With the contribution rate $C_{j}$ defined politically and remaining flat for each person regardless of their respective risk profile (and, hence, associated expected costs) and the security margin $S M_{i}$ set taking the expected deviation from the mean cost (e.g. due to the low quality of past data) for a given confidence level and potential price increases (trends) into account, these expected costs $\left(\operatorname{Cost}_{i}\right)$ and the scheme's administrative costs $\left(A_{j}\right)$ define the subsidy amount per person.

To define the administrative costs $\left(A_{j}\right)$ for MHI schemes operating in different operational health districts in Cambodia, a tendering process adapted from the one that is already applied by the Ministry of Health for health equity funds can be used. Under this process, in order to operate an MHI in one "cluster" of Cambodia's 81 operational health districts (usually between three and five districts together) and to be eligible for participation in the subsidy mechanism, interested operators (currently NGOs) would respond to a Ministry of Health (or the newly established SHP agency) tender with an offer specifying $A_{j}$. In line with the integration of health equity funds and MHI activities within a single scheme and to enhance operator efficiency, tenders would be for the combined cost of the operation of health equity funds and MHIs in one cluster. However, if the proposed approach is applied only to MHIs, $A_{j}$ would only describe the additional administrative cost of running the MHI beyond the cost of operating the health equity fund.

Figure 6 conceptually illustrates the effect of the subsidy mechanism with a politically set flat contribution. Areas A and C are the subsidy payments to the MHI scheme. Area B is excess income earned on low-risk insured. In a contributory risk-adjustment mechanism, some or all of this contribution could be transferred to the risk subsidy fund. However, to reduce the complexity of the system, it is suggested to leave this revenue with the MHI scheme for the time being and have SHP operators use any excess income to offer a lower $A_{j}$ 


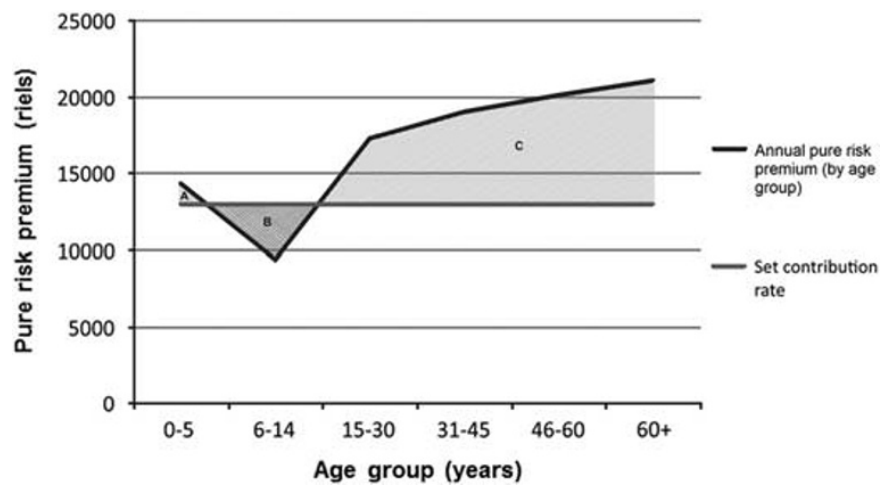

Figure 6. A conceptual illustration of applying a subsidy with a flat rate contribution.

in the tendering process. To ensure that a certain amount is spent on the insurance education of the target group, minimum requirements can be defined and funded. ${ }^{21}$

\section{Advantages of the approach}

The risk-adjusted subsidy approach strengthens the demand side of the health financing system, both with regard to services covered in a pre-paid benefit package as well as the population covered. A politically defined contribution rate payable by each insured member regardless of their risk profile would enhance the affordability of the scheme, while the extended benefit package would increase its attractiveness. Both aspects are likely to contribute to greater affiliation of members to the MHI scheme and, thus, enhance revenue generation as well as the achievement of the government's desire to move closer to universal health coverage.

The mechanism offers an interesting way of benefiting from the local presence of SHP and MHI operators, while at the same time shifting higher risks from local MHI pools into a nationwide pooling mechanism. Combining tax and insurance financing, it offers a "single-window" approach to the inclusion of vulnerable groups. This single-window approach helps to overcome fragmentation in the health system resulting from multiple single-purpose programmes. For example, the costs for obstetric care, the treatment of chronic illnesses or HIV services can be reflected in the cost curve of the risk-adjusted subsidy approach and, thus, be integrated into the benefit package offered by the insurance schemes. Inclusion of services for higher risk subgroups would greatly enhance equity in access to health care. The flat contribution rate would reduce the financial burden of higher risk groups without pricing those with lower risks out of the system.

Participation in the subsidy mechanism would require MHI operators to adhere to data management and operational standards set by the Ministry of Health or the National Social Health Protection Fund currently under consideration for the informal sector. The risk-adjusted subsidy approach, unlike subsidies for actual health costs or administrative

21 The defined subsidy would allow for national awareness campaigns jointly run by the Ministry of Health, National Social Health Protection Fund and scheme operators. 
costs, is relatively easy to monitor and verify. Subsidy payments are based on easy-toverify parameters of insured members: their age, gender and location (i.e. the scheme they are a member of). The subsidy is paid for the expected costs caused by each member. The MHI scheme is responsible for managing its expenses, can retain any surplus (as the schemes operate on a non-profit basis, the surplus cannot be extracted and is retained within the scheme), but also has to bear its own losses. This retains an incentive for scheme managers to run efficient operations, monitor health providers closely and continue innovating on how to best deliver insurance to the informal sector. Furthermore, as the administrative costs per insured decrease as more households are covered, scheme operators will aim to cover as many households as possible, as this increases the financial viability of the insurance scheme, regardless of the subsidy. The interest of scheme operators in maximising their insurance outreach is, therefore, aligned with the government's interest in having as many people covered as possible. Such a fixed ex ante subsidy approach, thus, increases efficiency in the health financing sector by (i) keeping the financial responsibility for overall scheme performance with scheme operators, (ii) retaining competition for lowest administrative costs through the tendering of operational districts and (iii) keeping in place incentives to reduce administrative costs even further through economies of scale. ${ }^{22}$

The continuous exchange of data between MHIs and the subsidy fund allows for the dynamic adjustment of the subsidy formula based on the actual claim experience of the various operators. This will increase the fit of the subsidy formula over time and take price developments in the health sector, as well as changes in the health-care supply side in specific districts or provinces, into account. In the case of a large discrepancy between initial cost estimations and actual costs incurred, for example, due to structural changes in the health-care market in the course of a year, an ex post correction of the subsidy paid can be considered.

\section{Conclusion}

The proposed mechanism is purely focused on the demand side and does not replace efforts to improve the supply side. However, it would help in reducing the current fragmentation of the SHP system by offering a "single-window" approach in order to support access to health services by high-risk populations, thereby increasing equity in access to care. If adopted, the approach would make a significant contribution to achieving the Government of Cambodia's objective of universal health coverage in all three of its dimensions, as it increases coverage of new segments of the population by offering an inclusive approach at an attractive contribution rate; it increases the services accessible by many people in the informal sector, which, due to their high risk profile, they would not otherwise be able to afford; and it reduces the direct costs for the user through a combination of pooling insurance and tax funding at two levels, combining the advantages

${ }^{22}$ For a general discussion on the efficiency aspects of risk adjustment see, for instance, Paolucci and Stoelwinder (2011). 
of local stewardship of the insurance operations with the strength of pooling high(er) risks at the national level.

Further, it is important to note that, while the focus of this paper has been on the MHI members of SHP schemes, services for identified poor members could also fall under the risk subsidy, with the remaining set contribution rate to be covered by a third party rather than the poor household. If implemented, this would constitute another major step towards a fully unified system.

Finally, whatever the approach eventually adopted by Cambodia in its attempt to achieve universal health coverage, the mechanism outlined above has the potential to be used in other, similar contexts with multiple and fragmented risk pools, as it offers both a suitable technical solution for the extension of SHP coverage to new population groups and an innovative mechanism that may be attractive to policymakers seeking to develop political will as well as policy momentum for this expansion of coverage.

\section{Acknowledgements}

The work on this concept development was undertaken when Ralf Radermacher, Siddharth Srivastava and Matthew Walsham were working for the Micro Insurance Academy (MIA). MIA and the Social Health Protection Association (SHPA) gratefully acknowledge the support received from Deutsche Gesellschaft für Internationale Zusammenarbeit (GIZ), which enabled them to undertake this work. The concept presented here reflects the view of the authors and not necessarily the position of any of the aforementioned organisations. The authors wish to thank the NGO that provided the data set used in this paper and the many stakeholders in the sector for the constructive discussions around this concept. The constructive comments of two anonymous reviewers and the editors of this journal, as well as of Barbara Broadway during the concept development, are also gratefully acknowledged. Finally, they thank Susan Sellars-Shrestha for her careful and thoughtful support in language editing.

\section{References}

Akerlof, G.A. (1970) 'The market for "lemons": Quality uncertainty and the market mechanism', The Quarterly Journal of Economics 84(3): 488-500.

Annear, P.L., Grundy, J., Ir, P., Jacobs, B., Men, C., Nachtnebel, M., Oum, S., Robins, A. and Ros, C.E. (2015) The Kingdom of Cambodia Health System Review. Health Systems in Transition, Vol. 5, No. 2, Manila, the Philippines: Asia Pacific Observatory on Public Health Systems and Policies.

Armstrong, J., Paolucci, F., McLeod, H. and van de Ven, W.P.M.M. (2010) 'Risk equalisation in voluntary health insurance markets: A three country comparison', Health Policy 98(1): 39-49.

Byass, P. (2009) 'The unequal world of health data', PLoS Medicine 6(11): e1000155.

GIZ (2014) Extending social health protection in Cambodia: How can health equity funds pave the way for universal health coverage?, Briefings for Health Financing Policy-Making in Cambodia No. 1, from http://www .p4h-network.net/wp-content/uploads/2014/10/Briefing-Note-Voluntary-enrolment-in-HEF.pdf, accessed 4 December 2015.

Index Mundi (2014) “Cambodia_Income distribution”, from http://www.indexmundi.com/facts/cambodia/incomedistribution, accessed 16 July 2014.

Mahal, A., Berman, P. and NandaKumar, A.K. (2002) Health expenditures and the elderly: A survey of issues in forecasting, methods used, and relevance for developing countries, from https://www.hsph.harvard.edu/ihsg/ publications/pdf/HealthExpendituresAndTheElderly.pdf, accessed 4 December 2015.

Ministry of Health (2012) Cambodia Socio-Economic Survey Analysis: Out-of-Pocket Expenditure on Health, unpublished document.

Ministry of Health (2013) Health Financing Policy, Final Draft (Ministry of Health), unpublished. 
Noirhomme, M., Meessen, B., Griffiths, F., Ir, P., Jacobs, B., Thor, R., Criel, B. and Van Damme, W. (2007) 'Improving access to hospital care for the poor: Comparative analysis of four health equity funds in Cambodia', Health Policy and Planning 22(4): 246-262.

Paolucci, F., Den Exter, A. and van de Ven, W.P.M.M. (2006) 'Solidarity in competitive health insurance markets: Analysing the relevant EC legal framework', Health Economics, Policy and Law 1(2): 107-126.

Paolucci, F. and Stoelwinder, J. (2011) Risk-Equalisation in Health Insurance Markets: Models and International Experience, research report, South Melbourne: Australian Centre for Health Research.

Radermacher, R., McGowan, H. and Dercon, S. (2012) 'What is the impact of microinsurance?' in C. Churchill and M. Matul (eds) Protecting the Poor: A Microinsurance Compendium. Vol. II. Geneva: International Labour Organization and Munich Re Foundation, pp. 59-82.

SHPA-Social Health Protection Association (2013) SHPA Position on Ministry of Health Subsidy for CBHI and Integrated HEF-CBHI Schemes (unpublished).

Smith, P.C. and Witter, S.N. (2004) Risk pooling in health-care financing: The implications for health system performance, Health, Nutrition and Population HNP Discussion Papers, Washington, DC: World Bank.

Sophal, O., Raingsey, P.P., Mony, K.E., Vannareth, M., Sothea, A., Youttiroung, B., Sovannara, C., Linda, P. and Sathia, L. (2010) Prevalence of Non-Communicable Disease Risk Factors in Cambodia, STEPS Survey Country Report, Ministry of Health, Kingdom of Cambodia.

Van de Ven, W.P.M.M. (2011) 'Risk adjustment and risk equalization: What needs to be done?' Health Economics, Policy and Law 6(1): 147-156.

Van de Ven, W.P.M.M. and Ellis, R.P. (2000) 'Risk adjustment in competitive health plan markets', in A.J. Culyer and J.P. Newhouse (eds) Handbook of Health Economics, Volume 1A, Amsterdam: Elsevier Science, pp. 755-846.

\section{About the Authors}

Ralf Radermacher heads the social protection programme of Deutsche Gesellschaft für Internationale Zusammenarbeit (GIZ) in Malawi. He was the deputy chairman of the Micro Insurance Academy, a non-profit technical assistance provider focused on pro-poor insurance, when the work presented in this article was undertaken. He is an economist by education, holding a degree from the University of Cologne, Germany.

Siddharth Srivastava is a health financing specialist working at the Swiss Tropical and Public Health Institute in Basel. He was a project officer at the Micro Insurance Academy when the work presented in this article was undertaken. He holds a post-graduate degree in Operational Research from Strathclyde Business School, Glasgow, Scotland.

Matthew Walsham is an independent development consultant and is currently working for the London School of Hygiene and Tropical Medicine. He was management adviser to SHPA in Cambodia at the Micro Insurance Academy when the work presented in this article was undertaken. He holds a master's degree in social anthropology of development from the School of Oriental and African Studies in London.

Chhorn Sao has more than 30 years of work experience in Cambodia, primarily in the health sector. $\mathrm{He}$ is a social health protection professional and currently acts as the institutional development consultant to the Social Health Protection Association (SHPA). He holds a master's degree of business and administration in finance and accounting from Build Bright University, Cambodia. 
Francesco Paolucci is associate professor and head of the health policy programme at the Sir Walter Murdoch School of Public Policy and International Affairs at Murdoch University, Australia, and an affiliated researcher at the School of Economics, Management \& Statistics, University of Bologna, Italy. He holds a PhD from Erasmus University Rotterdam, the Netherlands.

This work is licensed under a Creative Commons Attribution 3.0 Unported License. The images or other third party material in this article are included in the article's Creative Commons license, unless indicated otherwise in the credit line; if the material is not included under the Creative Commons license, users will need to obtain permission from the license holder to reproduce the material. To view a copy of this license, visit http://creativecommons.org/licenses/by/3.0/ 